\author{
Pablo "Manolo" Rodríguez \\ Universidad de Buenos Aires \\ manolo1416@yahoo.com
}

\title{
Capitalismo, archivo e información
}

\section{Capitalismo, archive and information}

\section{Resumen}

Este texto intenta resumir los principales ejes del libro Anarchivismo. Tecnologías políticas del archivo, de Andrés Maximiliano Tello. Dentro del llamado archival turn, la obra se enfoca en una caracterización del capitalismo arcóntico, que refiere a un proceso de acumulación capitalista que tiene a los datos y a los registros, en su versión informacional, como su principal activo. Se repasa para ello los aportes de algunos autores de la filosofía francesa postestructuralista (M.Foucault, G.Deleuze y J.Derrida), se los vincula con las reflexiones de otro filósofo central para la comprensión de los desafíos que plantea la noción de información, como J-F. Lyotard, y se destacan las tensiones entre los conceptos de memoria, huella, inscripción en diversos terrenos.

Palabras clave: Archivo, anarqueología, información

\begin{abstract}
This text tries to summarize the main axes of the book Anarchivismo. Tecnologías políticas del archivo, by Andrés Maximiliano Tello. Within the so-called archival turn, the work focuses on a characterization of arcontic capitalism, which refers to a process of capitalist accumulation that has data and records, in their informational version, as its main asset. To this end, the contributions of some authors of poststructuralist French philosophy (M.Foucault, G.Deleuze and J.Derrida) are reviewed, then linked to the reflections of another central philosopher for the understanding of the challenges posed by the notion of information, such as J-F. Lyotard, and finally the tensions between the concepts of memory, imprint, inscription in different terrains are highlighted.
\end{abstract}

Keywords: Archive, anarchaeology, information.

I.

Anarchivismo. Tecnologías políticas del archivo es, en principio, un libro de filosofía contemporánea. Emplea a los principales autores de la filosofía francesa, como Michel Foucault, Gilles Deleuze, y Jacques Derrida, para realizar una caracterización original del capitalismo contemporáneo en términos del archivo, de la consolidación de una política del archivo que se vuelve nodal para comprender cómo funciona hoy el capitalismo. Esto quiere decir que el 
artefacto que pone a andar su autor, Andrés Maximiliano Tello, dialoga constantemente con la obra de Marx y también con la de los autonomistas italianos, encargados justamente de enlazar el marxismo tradicional y la filosofía francesa teniendo como norte el análisis de las condiciones actuales del capitalismo. Y se trata, desde ya, de una nueva apuesta por la arqueología realizada por Foucault en la década de 1960.

Sin embargo, no cabe esperar en este libro un panegírico de estos autores, una pared de palabras, ya sea derridianas, foucaultianas o deleuzianas, que sólo funcionan para los ya convencidos y dejan afuera a quienes no frecuentan estos terrenos. Hay en Tello una toma de posición que se aleja de la comodidad del elogio:

"Ni Foucault ni Deleuze son enfáticos en describir al archivo como una máquina social que produce lo contemporáneo, es decir, que opera moldeando nuestras percepciones y discursos no solo sobre el pasado sino que, principalmente, opera definiendo la actualidad, en el despliegue de una economía de los registros y de una violencia archivadora que no deja de funcionar bajo nuevas formas" (Tello, 2018; 48)

Se sabe que la literatura anglosajona inventa sin cesar nuevas modas a las que le pone el nombre de giro: giro lingüístico, giro afectivo, giro informacional. Ahora sería el turno del archival turn. Anarchivismo podría inscribirse en ese giro, a condición de que se admita su espesor propiamente filosófico. Y ese espesor está constituido por el problema de la información, a partir del cual se redefinen los términos de este campo semántico: registro, archivo, memoria, museo, huella, inscripción.

II.

En una primera y rápida mirada, el archivo se relaciona con la acumulación. Karl Marx escribió El capital en el British Museum, contemplando el show de la rapiña del imperio británico. La acumulación originaria de capital fue analizada con la vista puesta en la acumulación de los orígenes de las demás culturas que la cultura occidental estaba comprimiendo, entre otras cosas, gracias a la constitución del mercado mundial. 
En una segunda escena, en la década de 1970, Michel Foucault señaló frente a un público plagado de psicoanalistas en Rio de Janeiro que esa acumulación de materia prima y de bienes necesitaba también de una política específica para la acumulación de los cuerpos. Así, en La verdad y las formas jurídicas, se puede leer que "para que haya plusganancia es preciso que haya subpoder" (Foucault 2008: 146). Foucault pretendió así complementar la mirada de Marx: el análisis de las sociedades disciplinarias es tan central como el de la formación del capital en términos económicos.

Es posible plantear que Andrés Tello, en Anarchivismo, está proponiendo analizar en esta senda un nuevo tipo de acumulación que responde a la constitución del archivo. Las políticas del archivo son fundamentales para comprender tanto la constitución del capitalismo como de las sociedades disciplinarias, y de la relación que vincula a estos términos.

Ahora bien, ante todo conviene despejar de qué tipo de acumulación se trata. El archivo no es un lugar donde se conservan cosas, expedientes, contratos, títulos. Es el producto heterogéneo de un conjunto de relaciones y tensiones sociales mucho mayor. No hay una objetividad del archivo porque es algo que se construye. ¿Cómo se construye? ¿Cómo se construye el museo, las huellas, las inscripciones? Para desmentir esta idea de que todo lo que se acumula es lo mismo, uno puede decir que la historia del capitalismo es la historia del proceso de acumulación, de cosas diferentes que a veces son colocadas en el mismo lugar y a veces son definidas de manera diferente. $\mathrm{Y}$ en el momento actual estaríamos en el momento de un nuevo tipo de acumulación.

$\mathrm{El}$ autor propone un movimiento interesante en el interior de la obra de Foucault cuando vincula la problemática del archivo con los juegos de veridicción. Se sabe que la noción de archivo pertenece al Foucault de la arqueología, anterior al de las relaciones de poder, esto es, de la genealogía. A fines de la década de 1960, Foucault se sintió encerrado en el archivo y salió de allí con el examen de las relaciones de poder. Pero a inicios de la década de 1980, ya inmerso en la cultura grecorromana y el primer cristianismo, Foucault se refirió a la anarqueología. Es entonces cuando Tello realiza el encadenamiento lógico que hace despegar a su libro: si la constitución del archivo es una de las formas para analizar el capitalismo, y esa forma es subsidiaria en el modo en que Foucault entiende la constitución del capitalismo en la estela de Marx, la arqueología se vuelve directamente anarqueología, porque no se trata de analizar los 
archivos y después las relaciones de poder, sino que al archivo se lo estudia en tanto está constituido por relaciones de poder. Esto abre un camino de investigación fructífero que hace fácil lo difícil. Abre un camino para problematizar realmente el problema del archivo, para salirse del sentido común acerca del archivo, de lo que significa hacer un archivo, no hablar de cosas archivadas. Cuando se hace un archivo, allí está toda la sociedad. No hay un solo dato, una sola información, nada de los 40 millones de millones de terabytes, que no estén construidos socialmente. Sin embargo, solemos olvidar que cuando se acumulan cosas, lo que se acumulan son construcciones sociales.

III.

Las construcciones sociales también son filosóficas. Es posible evocar en este recorrido otra escena, más antigua, que transcurre en el diálogo Timeo de Platón. El Timeo es un diálogo tardío analizado por muchos, entre ellos Jacques Derrida, alguien muy presente en Anarchivismo, en un texto precioso que se llama Khôra. En este diálogo, el "personaje" llamado Timeo ensaya una cosmología que explica los comienzos del universo, y con una notable ironía nos dice que es un intento de cosmología. Una vez que Sócrates le cede la palabra y desaparece del diálogo, algo que es muy curioso en los diálogos de Platón, Timeo advierte que lo que va a contar no pertenece ni al mythos ni al logos, que no hay implicaciones coherentes sobre el comienzo del universo e incluso se permite bromear sobre el carácter verosímil e inverosímil de un mito, invitando a los escuchas a admitir que por lo menos su relato tiene las características de un mito verosímil.

Timeo se pregunta de qué modo se vincula lo inteligible a lo sensible. Algún modo de comunicación debe haber, y este modo se llama chóra, según la trasliteración que correspondería al español, no al francés de acuerdo al título del libro de Derrida. Como no puede definir chóra, como no puede decir esta o esto es la o el o lo chóra, multiplica las imágenes y las representaciones para hacerse una idea vaga de lo que es o no es. Así, chóra aparece sucesivamente como un receptáculo, una nodriza, una madre al lado del padre que es lo inteligible y su hijo que es la naturaleza, una cosa donde se imprimen otras cosas -las ideas, las cosas sensibles, no se sabe-, algo de lo que no se puede decir que sea esto o aquello, que participa de lo eterno pero de un modo extraño, porque de hecho no se puede decir que sea algo permanente, es algo que en realidad no tiene ninguna característica en sí. Hay algo material en la 
chóra, pero es un material que no admite la destrucción y que permite el emplazamiento de todo lo que es y sí puede ser destruido.

Chóra está en el medio del ser y el devenir, y de hecho es la nodriza del devenir. No se sabe si chóra está antes o después de la organización del universo por parte del demiurgo, no se sabe si está antes o después del origen, porque si el universo es básicamente el paso del desorden al orden, chóra es desorden, orden, lo que permite que sean los dos sin ser ninguno, algo con lo que el demiurgo se encontró o que directamente creó.

Después de todo esto Timeo reconoce que desarrolló la exposición insólita. Habló de algo que puede recibir todas las determinaciones sin tener determinación última. Y ni siquiera puede admitir esas determinaciones como sus propiedades. También dijo de eso que es tan extraño que no se puede hablar de él directamente, sino tan sólo inducir que puede existir a partir de la existencia de otras cosas, a las que da lugar sin determinarlas. Y también aclara que eso no puede ser pensado como un origen, y a la vez tampoco como un producto. Parece estar más allá del tiempo y es la condición de posibilidad del espacio.

Este relato viene a cuento de que Anarchivismo se pregunta cuál es el soporte de las inscripciones de los signos de los discursos y de las imágenes; o sea, cuál es la condición de posibilidad de la mera acción de archivar, en qué se archiva. Vuelve entonces Derrida, interpretando ya no a Platón, sino a Antonin Artaud y su curiosa idea del subjectile.

"El subjectile es lo que está por debajo como materia o cuerpo, soporte o superficie aunque no sea ni lo uno ni lo otro, pero al mismo tiempo el subjectile perfora el cuerpo del soporte, la pantalla o el lienzo, pues activa un proyectil, lo que eyacula o lo que brota de una inscripción, aquello que trastorna tanto al sujeto como al objeto de una obra (...) Entre el óleo y la tabla, la tinta y la hoja, el ícono del monitor y la computadora, el subjectile se extiende pasivamente para soportar las marcas del pincel, la pluma o el teclado, aunque tiende a resistir igualmente cualquier figuración. El subjectile atraviesa las fronteras de la superficie de inscripción, y al mismo tiempo les da forma." (Tello, 2018; 142-145). 
Esto es fundamental para entender el funcionamiento del "capitalismo arcóntico", esto es, de un nuevo modo de funcionamiento de la acumulación, que es un gesto propiamente capitalista, a partir de la versión moderna, actual, de la chóra y la versión moderna, actual, del subjectile, que se llama información. La condición de posibilidad de todos estos millones de 40 mil millones de pitibytes es la existencia de una cosa que es muy difícil de definir porque tiene que ver con todo esto, indefinible, que es la información. Hasta hace medio siglo, todo lo que podía acumular el capitalismo eran cuerpos y cosas, y cuerpos con cosas, pero a partir de entonces el capitalismo puede acumular datos, que no tiene que ver con lo que la estadística recogía como datos en el siglo XVIII o XIX o con los registros del Imperio Romano. Es un cambio en las condiciones de posibilidad: hoy todo, absolutamente todo, puede ser convertido en dato. Por lo tanto, todo puede ser acumulado en otro registro, básicamente en su dimensión informacional. La asimilación de dato con información es compleja y discutible, pero no lo es que la información sea la condición de posibilidad de que todo sea "datificable", y por lo tanto acumulable, y que este proceso sea contemporáneo a la acumulación de las cosas, de los cuerpos, de los objetos. Ahora se pueden acumular sensaciones y emociones por el efecto de la información; esto es, por el hecho de que todo se puede digitalizar.

IV.

Cuando Jean-François Lyotard escribió en 1979 La condición posmoderna, muchos intelectuales "de izquierda" hicieron fila para criticarlo. Vale la pena leer lo que dice 40 años después. Lyotard se propuso analizar filosóficamente un cambio tecnológico, lo cual supone descartar el camino fácil de correr detrás de cada novedad para insertarla en una matriz social o económica que deja la tranquilidad, para el analista, de que nunca pasa nada nuevo.

Ese libro fue escrito a pedido del gobierno del Québec, la Canadá francesa, como una suerte de balance "cultural" al informe llamado La informatización de la sociedad, conocido como Informe Nora-Minc por el apellido de sus firmantes, que encargó a su vez el gobierno francés para responder a la pregunta “¿cómo debe prepararse Francia para la nueva época signada por las tecnologías digitales?". En ese entonces, los proyectos, públicos, privados y mixtos, sobre la digitalización a nivel masivo solía ser patrimonio de estrategas ubicados en general en el liberalismo. Era un problema "de la derecha" que Lyotard, proveniente de "la izquierda", se 
atrevió a disputar. La condición posmoderna fue estigmatizada alrededor de la famosa "caída de los grandes relatos" pero el tema que aborda es, precisamente, qué va a pasar cuando la acumulación capitalista comience a concentrarse en los datos, y no sólo en los objetos o las personas. Tanto ese libro como Lo inhumano. Charlas sobre el tiempo, donde dio cuenta de algunos aspectos adicionales de la digitalización del mundo, son de una gran actualidad. Planteó, entre otras cosas, esto que dice Tello:

“[L]a acumulación capitalista se configura mediante la desapropiación que opera en el registro de los bienes inmateriales, es decir mediante la privatización de huellas de la existencia común (...) [Se] ha intensificado el proceso de acumulación permitida, aunque esta vez ya no sólo mediante la usurpación de las tierras comunales, la expulsión de campesinos y la mercantilización de la fuerza de trabajo, que es el proceso que analizó Marx, sino que además mediante una axiomatización del acervo cultural de los pueblos y el conocimiento colectivo" (Tello, 2018; 246-248).

Existe entonces un nuevo proceso de expropiación, fundamental para el establecimiento de un nuevo proceso de acumulación. Es una expropiación que se produce porque todo es datificado y datificable, por lo cual la extensión del archivo es infinita. Baste una cifra mencionada en Anarchivismo: el Visual China Group, una empresa que acumuló los derechos de propiedad de la empresa CORBIS, fundada por Bill Gates en 1989, tiene 65 millones de fotografías originales. Pero todavía no pudieron ser digitalizadas en su totalidad. Las que no se pudieron digitalizar están afectadas por el paso del tiempo en un búnker a 70 metros bajo tierra en Filadelfia.

La diferencia entre acceso y propiedad es una de las novedades que trae la información al reino de la acumulación capitalista. Así, por ejemplo, una empresa como KetImage regula el acceso a archivos cuya propiedad es de China Group. Lo que no fue digitalizado no pertenece a China Group sino a Bill Gates. En esta triada, entre las cosas que fueron acumuladas, las que fueron digitalizadas y la digitalización misma que de todas maneras no es una propiedad, se 
puede ver la complejidad de la información, trabajada entre otros por Lyotard. No se trata de una duplicación de algo "real", sino una multiplicación combinada con una fragmentación.

En relación con esta complicada trama de expropiación se levantan lo que el autor llama las máquinas anarchivistas. Son ensamblajes de materialidades e intensidades, es decir, tecnologías de registro, cuerpos y efectos que gatillan la invención de nuevos espacios y relaciones de gobierno, que tienen que oponerse a las relaciones de gobierno que establecen CORBIS, Ket Image, China Group, Facebook, Google, etc. Se habla de una materialidad que está cargada de intensidades afectivas que deben ser irreductibles al dato.

El ejemplo del dictado de una clase es ilustrativo. Una clase es un hecho muy analógico. Hay voces, miradas, cuerpos. El desafío actual es que pase allí algo que no pueda ser digitalizarlo. Obviamente, una clase puede ser registrada y visualizada por cualquiera, pero eso que se ve y se escucha no es todo lo que pasa en lo presente. Ahora bien, si uno quiere dar una clase como un autómata, que es lo que hacen muchos dando clases, efectivamente es mejor que sea virtual, no se necesita la simultaneidad de la presencia. Esto no tiene que ver con una especie de resistencia "ideal" a la información, al dato, sino con el hecho de que hay que tener mucho cuidado con aquello que es registrable o no, y que debería ser posible para todos crear todo el tiempo hechos no registrables, porque aun cuando los registremos, se escapará el famoso aura de Benjamin, el "aquí y ahora", la "manifestación irrepetible de una lejanía" que sin embargo está presente.

El famoso tema de reproductibilidad técnica benjaminiana valía para la obra de arte. Hoy se aplica para la vida social, para la vida cotidiana, y no es mera reproductibilidad. Nosotros nos contactamos mediante algoritmos, establecemos un lazo social que es inmediatamente técnico. Y esto, lejos de provocarnos un prejuicio anti-técnico inútil, nos obliga a detenernos en una cuestión conceptual relativa a la distinción entre memoria, huella, inscripción, archivo, museo.

V. 
Dice Andrés Tello en Anarchivismo que es necesario romper con la metonimia operada entre memoria, identidad e interioridad: “[E]l funcionamiento de la memoria está marcado no solo por la repetición y la alteración de cualquier identidad ante el recuerdo y el objeto recordado, sino también por la transducción del sujeto que recuerda" (Tello, 2018; 176, destacado en el original).

Transducción es una noción científica y técnica que ha sido tomada por Gilbert Simondon para estudiar los sistemas de transformación de cualquier proceso, sea natural, artificial, cultural y/o social. En el caso de la memoria, se trata de una actividad, no de una cosa, que "está caracterizada menos por el sello de la continuidad que por la grafía discontinua de sus operaciones.

"En estricto rigor, el concepto de designa fundamentalmente un proceso que recrea y altera las impresiones de lo pretérito, dislocando en su irrupción nuestra propia existencia temporal. Todo ocurriría entonces como si la inusitada y reciente expansión de los archivos expresara en última instancia la capa de materialización de capacidad de memoria que pese a todo no es una memoria" (Tello, 2018; 177, destacado en el original).

La memoria es algo exterior, algo que se sabe desde la vieja condena a la escritura pronunciada en el diálogo Fedro de Platón.

Problematizado el vínculo entre memoria e interioridad, queda el otro: memoria e identidad. Se trata de un tema vinculado a las luchas que todos conocemos muy bien. Aquí el proceso a desandar es intricado. Comencemos por decir que hay una relación fundamental entre memoria y materialidad, expresada en la noción misma de información biológica. La información contenida en la materialidad biológica se transformó en la sede de una disputa por la definición de los procesos de apropiación, el establecimiento de una contrahistoria y la posibilidad de reescribir la memoria.

Las dictaduras latinoamericanas de los años 1970 buscaron quebrar la continuidad de la memoria, generar un hueco entre generaciones, refundar un orden temporal en sentido inverso al que proponían los revolucionarios franceses en 1789 cuando crearon un nuevo calendario. En el 
caso particular de la dictadura argentina, los militares resolvieron lanzar un plan doble: desaparición de algunos cuerpos y apropiación de otros, concretamente los bebés que debían ser criados y educados en otro contexto "no marxista" como formar de sobreimprimir un tiempo al tiempo que estaban haciendo desaparecer. Las Abuelas de Plaza de Mayo, a través del llamado "índice de abuelidad”, lograron deshacer esa historia.

En ausencia del cuerpo de los padres, las Abuelas, con el auxilio de prestigiosos genetistas, lograron establecer una línea de filiación que no necesitaba del material genético de los padres para determinar una relación entre una hipótetica abuela o abuelo y su hipotético nieto o nieta. Los bebés apropiados por la dictadura comenzaron a transformarse en nietos recuperados: una reapropiación contra una apropiación original, producto de un secuestro y de una desaparición.

Es enorme el significado de este proceso para los temas relacionados con el archivo. Los militares buscaron borrar las huellas de sus delitos, pero resulta que la biología deja otras huellas que permiten reconstruir las otras. El ADN mitocondrial, la materialidad de la huella que se utiliza para constituir el "índice de abuelidad", se convierte en un archivo de memoria, externa y a la vez interna a una familia que viene a reconstruir, al mismo tiempo que ese archivo es construido por la historia social.

Si los biologicismos suelen ser de derecha y los culturalismos suelen tener un tinte progresista, sobre todo si ambos son puestos en situación de enfrentamiento, tenemos aquí un curioso pasaje. Los militares que ordenaban la expropiación de bebés de las personas que iban a hacer desaparecer eran estrictamente culturalistas: esos bebés, en otro contexto, eran rescatables mediante una educación y una crianza cristianas. En cambio, las Abuelas de Plaza de Mayo deben ser lo suficientemente biologicistas como para confiar en la genética y afirmar, así, que la pertenencia a una familia es un hecho estrictamente biológico. Es obvio que lo es, pero también es preciso saber que este combate de memorias y de olvidos, de culturas y de biologías, es también una disputa por el sentido de ese término: familia. Por una vez, la biología, siempre sospechada desde las ciencias humanas y sociales, cumplió un papel diferente al de justificar las desigualdades y las matanzas.

A partir de este ejemplo se vuelve necesario pensar y repensar el problema de la huella, de la inscripción y de la evidencia del archivo. En todos los casos se vuelve fundamental la 
problematización del registro. La noción de información en biología, la que permite construir el índice de abuelidad, señala que lo natural elabora su propio registro. Y hoy es lo artificial nos muestra que también registra y, lo que es más, que acumula y registra procesos, ya no sólo cosas, personas o sus representaciones. Los algoritmos que regulan nuestras apps y todos nuestros dispositivos digitales trabajan registrando su propia actividad. Esto quiere decir que, ya en lo natural, ya en lo artificial, nos encontramos con registros no humanos, no porque hayan venido de Marte, sino porque la actividad de registro, aunque su resultado actúe en la sociedad y en la cultura, no está gobernada únicamente por humanos.

Así, pues, Anarchivismo desnaturalizar el problema del archivo y lo transforma en un problema digno para la filosofía y las ciencias sociales. Esa dignidad está dada por la importancia de las políticas del archivo para describir la constitución y transformación del capitalismo en la era de la acumulación de información. 


\section{Bibliografía}

Derrida, Jacques. (1995). Khôra. Córdoba: Alción.

Foucault, Michel. (2008). La verdad y las formas jurídicas. Barcelona: Gedisa.

Foucault, Michel. (2005). La arqueología del saber. Buenos Aires: Siglo XXI.

Lyotard, Jean François. (1998). Lo inhumano. Charlas sobre el tiempo. Buenos Aires: Manantial.

Lyotard, Jean François. (1987). La condición postmoderna. Informe sobre el saber. Madrid: Cátedra.

Marx, Karl. (1999). El Capital. Tomo I, vol.1: El proceso de formación del capital. Buenos Aires: Siglo XXI.

Platón (1999). Timeo. Buenos Aires: Colihue.

Simondon, Gilbert. (2008). El modo de existencia de los objetos técnicos. Buenos Aires: Prometeo.

Tello, Andrés. (2018). Anarchivismo. Tecnologías políticas del archivo. Buenos Aires: La Cebra.

Wulff, Guillermo. (2009). Las Abuelas y la genética. El aporte de la ciencia en la búsqueda de los niños desaparecidos. Buenos Aires: Abuelas de Plaza de Mayo. 